\title{
Ethnographic Study of Perspective and Attitude of Breastfeeding Mothers Towards the Use of Elaeis Guineensis Sap as Galactagogue Among Igbo Women of Southeastern Nigeria
}

\author{
Chikezie J. OKAMKPA1, Chike I. ANIBEZE' ${ }^{1}$ Ignatius I. OZOR ${ }^{1}$, Ikenna K. NDU², Uchenna A. UMEH \\ Enugu State, Nigeria
}

\section{ABSTRACT}

OBJECTIVE: As an age-old traditional practice, nursing mothers from southeastern Nigeria use the Elaeis guineensis sap (from the oil palm tree also referred to as palm wine) to induce and sustain lactation a few hours after delivery. This practice is still ongoing to date, despite the scarcity of clinical data supporting its efficacy and safety. This study aimed to generate preliminary data on the prevalence, perceptions, and behaviors related to the use of Elaeis guineensis sap as a galactagogue.

STUDY DESIGN: Mothers who had breastfed or breastfeeding at the time of the survey, were invited to complete a questionnaire that asked about their, perceptions, efficacy, and possible side effects of Elaeis guineensis sap on both mother and child during breastfeeding. Chi-square analysis was used to conduct data analysis.

RESULT: A total of 5002 mothers completed the survey with $61 \%$ reporting use of Elaeis guineensis sap (palm wine) following parturition. Most of the respondents $(73 \%)$ attained tertiary education. The practice was mostly recommended by direct relatives (38\%) while the commonest reason for this practice was perceived insufficient milk production $(32.2 \%)$. The majority of the respondents $(52 \%)$ were satisfied with the outcome while $44 \%$ reported no negative side effects.

CONCLUSION: The use of Elaeis guineensis sap by mothers following parturition is common in southeastern Nigeria. However, randomized control studies are needed to provide evidence for the efficacy and safety of this plant product. This will be relevant to the formation of intercultural health policies which will value and respect the positive cultural practices of a people.

Keywords: Elaeis guineensis sap, Galactagogue, Nigeria, Palm wine, South-eastern

Gynecol Obstet Reprod Med 2022;28(1):31-37

${ }^{1}$ Department of Anatomy College of Medicine Enugu State University of Science and Technology Parklane GRA Enugu, Enugu State Nigeria

${ }^{2}$ Department of Pediatrics College of Medicine Enugu State University of Science and Technology Parklane GRA Enugu, Enugu State Nigeria

${ }^{3}$ Department of Obstetrics and Gynaecology College of Medicine University of Nigeria Ituku-Ozalla Enugu

Address of Correspondence:

Chikezie J. Okamkpa

Department of Anatomy, College of

Medicine, Enugu State University of

Science and Technology, Parklane GRA.

Enugu, 400001 Enugu State, Nigeria

jude.okamkpa@esut.edu.ng,

keskefioga1@gmail.com.

Submitted for Publication: 31.08.2020 Revised for Publication: 09.09.2020 Accepted for Publication: 08.07.2021 Online Published: 03.09.2021

ORCID IDs of the authors: $\quad$ CJO: 0000-0002-2875-7246

CIA: 0000-0002-9585-5356, IIO: 0000-0002-9071-735X

IKN: 0000-0003-2198-5614, UAU: 0000-0001-5516-4684

\begin{tabular}{|c|c|}
\hline \multirow{3}{*}{ 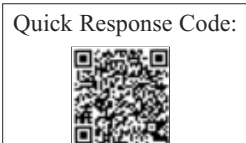 } & Access this article online \\
\hline & $\begin{array}{l}\text { Website: www.gorm.com.tr } \\
\text { e- mail: info@gorm.com.tr }\end{array}$ \\
\hline & DOI:10.21613/GORM.2021.1148 \\
\hline
\end{tabular}

How to cite this article: Okamkpa CJ. Anibeze CI. Ozor II. Ndu IK. Umeh UA. Ethnographic Study of Perspective and Attitude of Breastfeeding Mothers towards the use of Elaeis guineensis Sap as Galactagogue among Igbo Women of Southeastern Nigeria. Gynecol Obstet Reprod Med. 2022;28(1):31-37

\section{Introduction}

Breastfeeding is perhaps the oldest practice in human history being a natural recourse to the maintenance of mammalian species integrity. Its health benefits for both mother and infant have been well documented (1). The World Health Organization (WHO) recommended that breastfeeding should be initiated early and preferably within the first hour of birth (2). This practice termed early initiation of breastfeeding (EIBF) stimulates breast milk production, produces antibody protection for the newborn, and reduces postpartum maternal hemorrhage $(3,4)$. Despite the known health benefits of EIBF, in many countries, a considerable proportion of newborns are not breastfed within the first hour of birth in accordance with the WHO recommendation (5). According to a report from the United Nations Children's Fund (UNICEF) and the World Health Organization (WHO), globally, only 2 out of 5 newborns began breastfeeding within an hour of birth in 2017, leaving an estimated 78 million new-borns to wait over 1 hour to be put to the breast, $(6,7)$. This delay is mostly associated with lactation failure commonly due to perception of insufficient breast milk production (8-10). Lactation failure whatever the cause may be is usually devastating because the use of 
breast milk substitutes increases the risk of morbidity and mortality among infants in developing countries, and these supplements are the most common cause of malnutrition (11). Thus, it requires immediate intervention. To stimulate breast milk production, a substantial number of women turn to the use of herbal galactagogues (a group of substances or medicines either proven or believed to aid lactation during initiation and maintenance stages, thereby increasing human breast milk supply) $(12,13)$. Studies conducted in the United States, Australia, Norway, Switzerland, and Canada estimated that $15 \%, 24 \%, 43 \%, 93 \%$, and $100 \%$ of breastfeeding women use herbal galactagogues respectively (14).

Mothers' breastfeeding decisions to use herbal galactagogues especially in the rural communities are shaped by social norms and cultural beliefs about nutrition $(12,15)$ thus interest in the use of herbal galactagogues can be explained by the fact that it is a fundamental part of the culture of the people who use them and nearly all cultures have promoted one substance or another as a galactagogue to encourage the synthesis and secretion of breast milk (16).

In Southeastern Nigeria, breastfeeding mothers live amidst nutritional norms and practices, which include a repertoire of knowledge about plants believed to provide additional nutrients to lactating mothers. They use Elaesis guineensis sap, the unfermented colorless exudate from tapped unopened spathe of the oil palm tree (Elaeis guineensis, Jacq) to induce and maintain lactation following parturition. The Elaeis guineensis sap is a traditional drink usually consumed as a nourishing beverage in some tropical countries $(17,18)$. This freshly collected sap has 7.2 of neutral $\mathrm{pH}$ and a very low content of ethanol i.e., $0.09 \%$. However, the sap undergoes spontaneous fermentation, which promotes the proliferation of yeasts and bacteria for the conversion of the sweet substrate into several metabolites mainly ethanol, lactic acid, and acetic acid (19)

From a public health perspective, it is of interest to develop intercultural initiatives that analyze consensus on local knowledge and practices of breastfeeding. The use of Elaeis guineensis sap as a galactagogue in the context of maternal-child health policies in southeastern Nigeria has scarcely been studied. This study examined the perception, attitude, and pattern of use of Elaeis guineensis sap amongst breastfeeding women in Igbo Communities of South Eastern Nigeria to enhance breast milk flow following parturition. This information will inform and direct future clinical research on the efficacy and safety of herbal galactagogues used in this part of the world.

\section{Materials and Method}

\section{Study area}

A cross-sectional descriptive and analytical study was designed to explore mothers' experiences with the use of Elaeis guineensis sap as a galactagogue to improve lactation and sources of information on these products. This study was carried out for nine months period from May 2018 to January 2019, involving mothers who attended the general outpatient department (GOPD), postnatal and immunization clinics at Uwani general hospital, Poly district hospital, and Enugu State University Teaching Hospital all within Enugu metropolis. Women who attended medical outreach programs for cervical cancer screening organized by the ACE Cancer Care Inc at Health centers in Akpoga Nike and OrbaNsukka all in Enugu State within the period of study formed part of the study.

Enugu State is one of the 36 States in Nigeria located between latitude $5^{\circ} 56^{\prime} \mathrm{N}$ and $7^{\circ} 00^{\prime} \mathrm{N}$ and longitude $7^{\circ} 00^{\prime} \mathrm{E}$ and $7^{\circ} 55^{\prime} \mathrm{E}$ of the Greenwich meridian. The State is bounded in the northeast by Ebonyi State, on the north by Benue and Kogi States, and to the west by Anambra State from which it was carved out in 1991 (Figure 1).

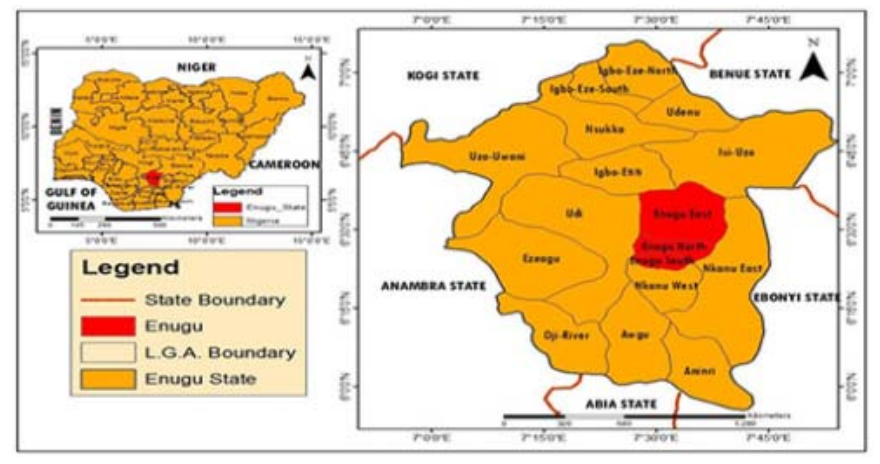

Figure 1: Map of Nigeria showing the area of study. Source: Geographic information systems.

\section{Study sample and selection process.}

A total of 5002 participants, 18 years and above, who had breastfed or currently breastfeeding their young were required to complete an in-depth semi-structured questionnaire, designed to elicit information efficiently on their experiences with the practice of using palm wine as a galactagogue. The questionnaire contained two sections. The first section captured participants' demographic information including age, marital status, educational attainment, occupation, parity, and history of the practice of exclusive breastfeeding. The second section identified participants' who had used palm wine as a galactagogue. It also assessed the reason for using the plant substrate, the pattern of use, including duration of use, the dosage used, recommendation source, perceived effectiveness as well as indicators of perceived effectiveness. It also assessed the onset and duration of the effect, level of satisfaction, and possible untoward effects to the mother and infant during and after breastfeeding.

Data collection began in May 2018 and ended in January 2019. Only data from participants who voluntarily signed informed written consent and completed the questionnaire were included in the study. Questionnaires were excluded from the data set when answers were incomplete or ambiguous and based on consensus by the researchers.

Data were entered and analyzed using SPSS version 23. Descriptive statistics which includes frequency and percentages were used to summarize categorical variables. 
The study was reviewed and approved by the ethics committee of Enugu State Ministry of Health Research Ethics Committee (MH/MSD/REC19/102: 10/01/2019). All procedures were performed according to the Declaration of Helsinki.

\section{Results}

A total of 5002 women from different states of the Nigerian federation but residing within Enugu state completed the questionnaire for this study. The participants were mothers between the age of 18 and $>68$ years, who had breastfed or breastfeeding at the time of the survey. Table I illustrates the sociodemographic characteristics of the study sample. The vast majority of respondents (97.4\%) were Igbos and mostly Christians (98.2\%). Most attained tertiary education (72.3\%), the rest either attempted or completed secondary and primary education $(21.6 \%$ and $5.3 \%$ ) respectively while $0.9 \%$ of the respondents had no formal education. Among the respondents who noted that they were employed, the majority $(62.4 \%)$ worked for Salary/wage, $25.4 \%$ were self-employed, while the rest were housewives, students, and retirees. The respondents had either given birth to and breastfed more than four children (39.3\%), three children $(23.4 \%)$, two children $(20.2 \%)$, or a child $(2.2 \%)$.

Among women surveyed, 61.1\% (n=3054) used Elaeis guineensis sap as galactagogue while 38.9\% $(\mathrm{n}=1948)$ declined this practice. $1.4 \%$ of the respondents, who admitted using Elaeis guineensis sap as a galactagogue, were not from the Igbo ethnic group. As presented in this survey, of the women who practiced the use of Elaeis guineensis sap to initiate and maintain lactation immediately after parturition as a galactagogue, the majority attained tertiary education $45.4 \%$ $(n=2271), 39.7 \%(n=1976)$ of them were Salary/wage earners, $25.4 \%(n=1271)$ were self-employed while $12.1 \%$ were either, students, housewives or elderly mothers who had retired from civil service. Most of them had breastfed more than four children (Table I).

Table I: Characteristics of study participants $(n=5002)$

\begin{tabular}{|c|c|c|c|c|}
\hline \multirow[t]{2}{*}{ haracteristics } & & \multirow[t]{2}{*}{$\begin{array}{l}\text { Total number of } \\
\text { Respondents } \mathrm{n}(\%)\end{array}$} & \multicolumn{2}{|c|}{$\begin{array}{l}\text { Use of palm wine immediately after } \\
\text { parturition }\end{array}$} \\
\hline & & & Yes $n(\%)$ & No $n(\%)$ \\
\hline \multirow[t]{5}{*}{ Ethnicity } & Igbo & $4873(97.4)$ & $2985(59.7)$ & $1888(37.8)$ \\
\hline & Hausa & $21(0.4)$ & $9(0.2)$ & $12(0.2)$ \\
\hline & Yoruba & $61(1.2)$ & $35(0.7)$ & $26(0.5)$ \\
\hline & Others & $45(0.9)$ & $23(0.5)$ & $22(0.4)$ \\
\hline & Total & 5000 & $3052(61.0)$ & $1948(39.0)$ \\
\hline \multirow[t]{4}{*}{ Religion } & Christian & 4914 (98.2) & $3005(60.1)$ & $1909(36.1)$ \\
\hline & Islam & $27(0.5)$ & $13(0.3)$ & $14(0.3)$ \\
\hline & African traditional religion & $61(1.2)$ & $36(0.7)$ & $25(0.5)$ \\
\hline & Total & 5002 & $3054(61.1)$ & $1948(36.9)$ \\
\hline \multirow[t]{5}{*}{ Marital status } & Single & $292(5.8)$ & $224(4.5)$ & $68(1.4)$ \\
\hline & Married & $4031(80.6)$ & $2374(47.5)$ & $1657(33.1)$ \\
\hline & Widow & $473(9.5)$ & $267(5.3)$ & $206(4.1)$ \\
\hline & Divorced /separated & $206(4.1)$ & $189(3.8)$ & $17(0.3)$ \\
\hline & Total & $5002(100)$ & 3054 (61.1) & $1948(38.9)$ \\
\hline \multirow[t]{5}{*}{ Level of education } & Tertiary & $3617(72.3)$ & $2271(45.4)$ & $1346(26.9)$ \\
\hline & Secondary & $1078(21.6)$ & $645(12.9)$ & $433(8.7)$ \\
\hline & Primary & $264(5.3)$ & $102(3.2)$ & $162(2.0)$ \\
\hline & Nil formal education & $43(0.9)$ & $36(0.7)$ & $7(0.1)$ \\
\hline & Total & $5002(100)$ & 3054 (61.1) & $1948(38.9)$ \\
\hline \multirow[t]{6}{*}{ Occupational status } & Working for Salary/wages & $3123(62.4)$ & $1979(39.6)$ & $1144(22.9)$ \\
\hline & Self-employed & $1271(25.4)$ & $737(14.7)$ & $534(10.7)$ \\
\hline & Student & $232(4.6)$ & $138(2.8)$ & $94(1.9)$ \\
\hline & House-wife & $177(3.5)$ & $93(1.9)$ & $84(1.7)$ \\
\hline & Retiree & $198(4.0)$ & $106(2.1)$ & $92(1.8)$ \\
\hline & Total & 5001 & $3053(61.0)$ & $1948(39.0)$ \\
\hline \multirow[t]{5}{*}{ Parity } & One & $172(3.4)$ & $107(2.1)$ & $65(1.3)$ \\
\hline & Two & $1233(24.7)$ & $828(16.6)$ & $405(8.1)$ \\
\hline & Three & $1451(29.0)$ & $872(17.4)$ & $579(11.6)$ \\
\hline & Four and above & $2146(42.9)$ & $1247(24.9)$ & $899(18.0)$ \\
\hline & Total & 5002 & $3054(61.1 \%)$ & $1948(38.9 \%)$ \\
\hline
\end{tabular}




\section{Breastfeeding characteristics and pattern}

All the respondents who used Elaeis guineensis sap during breastfeeding did so for various reasons. The vast majority of respondents $(52.5 \%, \mathrm{n}=1612)$, reported that while breastfeeding, they felt as though they were not making enough milk (perceived insufficient milk supply) to meet the needs of the neonate. $22.7 \%(n=695)$ of the respondents used it for insufficient milk supply as diagnosed by a health professional while $18.7 \%(\mathrm{n}=574)$ practiced its use as part of tradition and culture. Respondents classified as "perceived insufficient milk supply" were women who had not previously been diagnosed with difficulty in breast milk supply by a health professional, however, they considered themselves as having low milk supply (Figure 2).

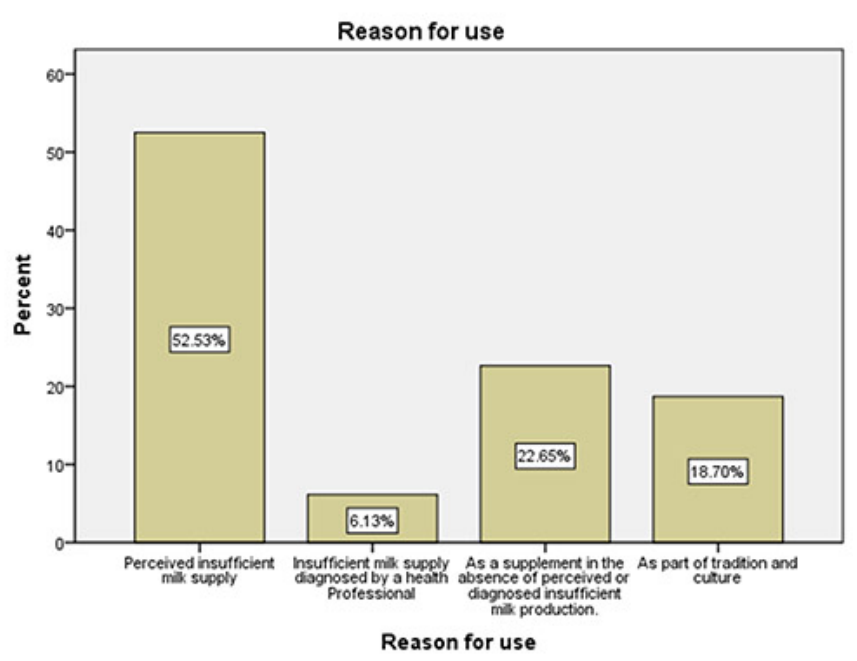

Figure 2: Reasons for using Elaeis guineensis sap as a galactagogue

\section{Sources of recommendation}

With regard to sources of information on the use of Elaeis guineensis sap to induce and sustain breast milk flow a few hours after delivery, many of the participants chose this practice based on recommendations from individuals (Figure 3), and in most cases, more than one source prompted the deci- sion. Respondents indicated that sources of the recommendation included advice obtained from family members such as older mothers and mothers-in-law 47\% ( $\mathrm{n}=1440)$, Husbands $14.8 \%(n=455)$, and friends $24.7 \%(n=756)$. Other reported that sources of information/recommendation were also from Mid-wives 5.4\% ( $\mathrm{n}=165)$, Lactation consultants'/ health worker $2.9 \%(n=88)$ and self-prescription $5.3 \%(n=162)$.

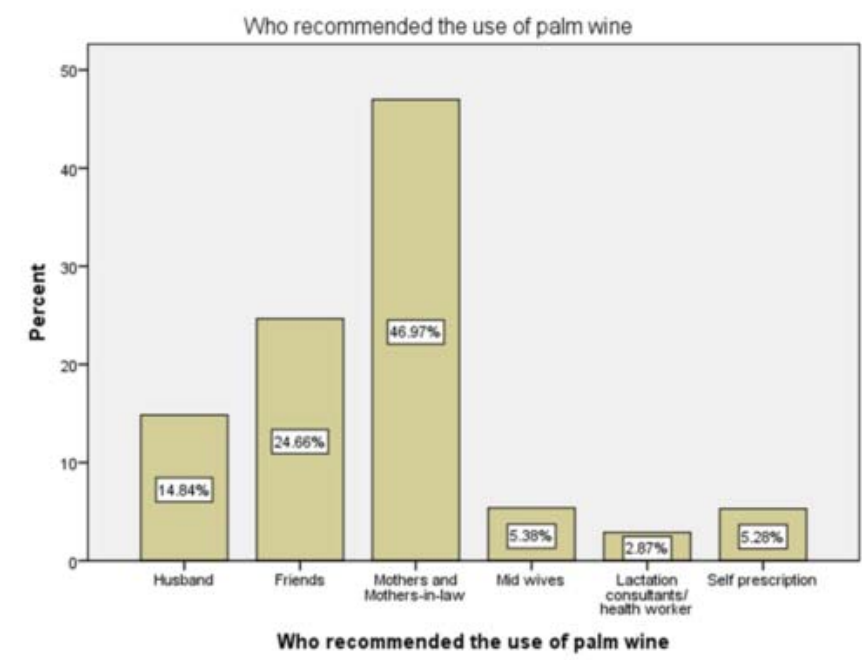

Figure 3: Sources of recōmmendation on use of Elaeis guineensis sap

\section{The pattern of use of Elaeis guineensis sap as a galacta- gogue}

Summaries of patterns of use of the Elaeis guineensis sap are provided in Table II. Most participants commenced it at various times following delivery of the baby, with 1538 (50.1\%) participants commencing as early as two to three days post parturition, and $1193(40 \%)$ starting immediately after delivery. $38.2 \%(n=1911)$ of the participants reported taking one or two glasses of Elaeis guineensis sap once a day to achieve the desired effect. Desired effects as reported by most of the participants were feeling of fullness $(54.2 \%)$. Other effects reported were, an obvious increase in the volume of expressed milk/leaky milk, infant perceived satisfaction, and changes in the duration of feeding sessions (Table II).

Table II: Pattern of use of palm wine as a galactagogue

\begin{tabular}{|c|c|c|c|}
\hline & & Frequency & Percent \% \\
\hline \multirow[t]{6}{*}{ Time of intake } & Immediately after delivery & 1193 & 38.9 \\
\hline & Two to three days after delivery & 1538 & 50.1 \\
\hline & Within a week after delivery & 326 & 10.6 \\
\hline & Two weeks after delivery & 3 & 0.1 \\
\hline & A month before delivery & 7 & 0.2 \\
\hline & Total & 3067 & \\
\hline \multirow[t]{6}{*}{ Quantity of intake } & 1 - 2 glasses once a day & 1911 & 38.2 \\
\hline & 2 - 5 glasses once a day & 549 & 11.0 \\
\hline & 1 - 2 glasses thrice a day & 484 & 9.7 \\
\hline & 2 - 5 glasses thrice a day & 29 & 0.9 \\
\hline & $>5$ glasses a day & 89 & 1.8 \\
\hline & Total & 3062 & \\
\hline
\end{tabular}


Perception of effectiveness, and safety of Elaeis guineensis sap

For this study, various ways to assess if the Elaeis guineensis sap was effective or useful were evaluated and referred to as "breastfeeding adequacy indicators". Selected quotations of the perceived effectiveness of oral intake of the sap during breastfeeding based on the participants' personal experience and observation are provided in Figure 4. A subjectively judged good increase in milk production was reported by $61.3 \%(n=3071)$ of the respondents. The most common indicator of effectiveness was the feeling of fullness $54.2 \%(n=1664)$. Other indicators mentioned by participants were an increase in the measured volume of expressed milk $25.4 \%(n=779)$, changes in the infant's perceived satisfaction and feeding behavior $19.3 \%(\mathrm{n}=594)$, as well as changes to the duration of feeding sessions (Figure 4).

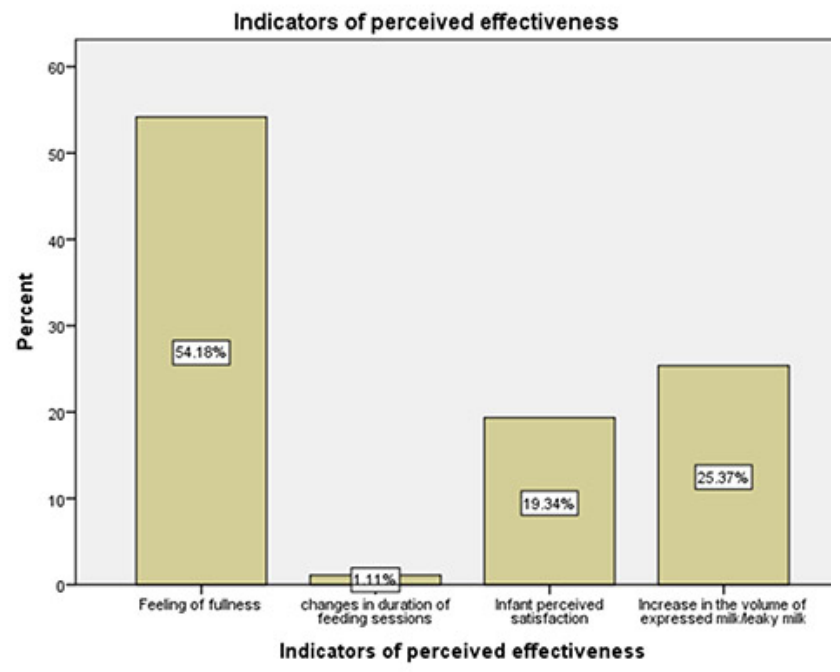

Figure 4: Indicator of perceived effectiveness.

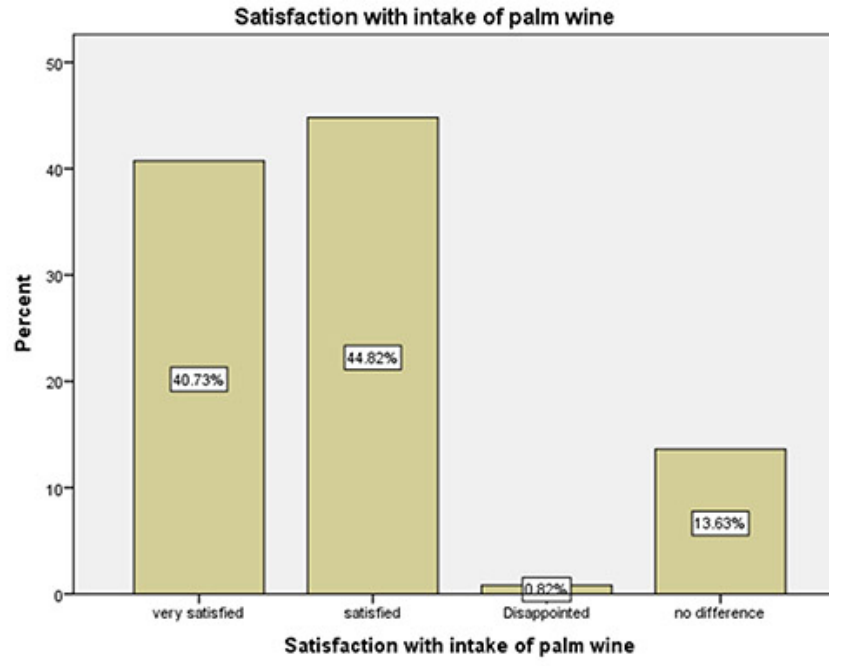

Figure 5: Satisfaction with the intake of Elaeis guineensis sap as a galactagogue

The majority of the respondents who admitted using Elaeis guineensis sap as a galactagogue $(72.2 \%)$ stated that no untoward effect or adverse outcome was observed while using palm wine during breastfeeding. However, 27.8\% reported side effects. The common adverse effects reported with the use of Elaeis guineensis sap were mostly drowsiness and diarrhea.

Despite the untoward effects reported, 2,617 (99.5\%) mothers who used Elaeis guineensis sap as galactagogue were satisfied with the breastfeeding practice. 25 mothers $(8 \%)$ were unsatisfied with their breast milk production after using palm wine as galactagogue while $417(13.6 \%)$ were unable to judge due to the simultaneous use of other approaches to increase breast milk supply including the use of conventional drugs and the "pumping method" through breast pumps

\section{Discussion}

Our study contributes to the limited data regarding the use of Elaeis guineensis sap (palm wine) to enhance breast milk flow after parturition, its perceived efficacy, and side effects in breastfeeding mothers and their infants. Insufficient milk supply is cited as a primary reason for early termination of breastfeeding, and is a very important concern for lactating mothers, with $30 \%-80 \%$ of breastfeeding mothers globally naming this as a major reason for breastfeeding cessation (14). These women resort to the use of natural galactagogues despite the scarcity of clinical data supporting their efficacy $(12,14)$.

Galactagogues are a group of substances or medicines either proven or believed to aid lactation during initiation and maintenance stages, thereby increasing human breast milk supply (13). Several conventional galactagogues such as metoclopramide, sulpiride, domperidone, and chlorpromazine have been used for the management of lactation failure $(8,13,20,24)$. These drugs are antagonists to dopamine which inhibits breast milk production (15) and are, however, associated with unwanted side effects such as sedation, depression, weight gain, gastrointestinal disturbances, headache, nausea, and dry mouth $(20,22,23)$.

Plant extracts commonly believed and scientifically proven to aid lactation include fenugreek (Trigonella foenum-graecum L.), blessed thistle (Cnicus benedictus), milk thistle (Silybum marianum), goat's rue (Galega officinalis), dates (Phoenix dactylifera), fennel (Foeniculum vulgare), Moringa oleifera and Hibiscus sabdariffa $(12,21)$. Many of these herbal substances have gained popularity in the Western world as galactagogues. Most of these herbs used for milk supply have been directly associated with oxytocic effects or are listed as having a galactagogue effect, whose mechanism is less understood. Despite the scarcity of clinical data on the actual increase of breast milk production following the use of the above, many women continue to use natural galactagogues (12).

Among very few previous studies that have aimed to explore mothers' perspectives and experiences of using pharmaceutical and herbal galactagogues, no study to date has sampled nursing mothers from southeastern Nigeria who has prac- 
ticed for decades the use of Elaeis guineensis sap (palm wine) to induce and sustain lactation few hours after delivery. This study addressed this gap by sampling mothers who had previously breastfed and/or presently breastfeeding to document experiences with, the safety of, and the usefulness of Elaeis guineensis sap as a galactagogue, as well as sources of information on this practice.

A notable finding of the present study was that the use of Elaeis guineensis sap (palm wine) as a galactagogue was relatively common among Christians, mothers of all works of life, with high academic exposure, in southeastern Nigeria. Cultural acceptance, low cost, accessibility, perceived efficacy, and safety might explain the reason for its high use in our study. This practice has been reported as a socio-cultural norm among Igbos (20). The recommendation of Elaeis guineensis sap (palm wine) as galactagogue supports this assertion. This recommendation was mostly from family members who usually transfer this practice from generation to generation.

As evident in this study, the use of Elaeis guineensis sap as galactagogues exists in various dosage forms. So also is the time of and duration of intake, thus making a comparison of effects challenging. Most of the respondents believed that the plant sap provides needed nutrients for lactation and promotes a sense of relaxation and self-efficacy as well.

We also assessed the subjective experience of potential side- effects. There are very limited data regarding the safety of the use of Elaeis guineensis sap as galactagogues. The sideeffects described by a few of the study participants were mostly minor complaints. The diarrhea symptoms reported are usually a result of the presence of microorganisms (25) from environmental contamination. Of note is the relatively low rate of sideeffects reported. Although the present study design is such that reliable conclusions cannot be drawn on the safety and potential risks of this plant exudate, its wide and generational acceptability evoke the potential need for further research.

\section{Conclusion}

From this study, the perception of the use of palm wine as a galactagogue to increase breast milk production is common among breastfeeding mothers of the Igbo ethnic group. Many of these mothers believe that palm wine can increase breast milk production and it is safe because it is natural and almost free of preservative products. The outcome from this study can be used to plan advanced clinical research on the use of Elaeis guineensis sap (palm wine) as galactagogue among breastfeeding mothers and eventually promote the use of this natural product as a galactagogue. Thus mothers will have a successful journey on breastfeeding as it will improve the quality of life for both mother and child.

\section{Limitations}

Limitations in this study are related to the reliance on self- reporting by participants. Self-reporting is associated with an increased risk of recall and responder bias.

\section{Recommendation}

Studies using laboratory animals as well as a randomized control study are needed to evaluate the findings of this study

Acknowledgment: We gratefully appreciate the cooperation of all participants in this study. We also thank the following individuals Chiamaka, Beatrice, Chioma, Innocent, Ossai, and Monday Nwankwo for their tireless contributions

Funding: This research received no external funding.

Competing interests: The authors declare no conflict of interest.

Consent to participate: All participants signed informed written consent before being enrolled in the study.

Availability of data and materials: The data supporting this study is available through the corresponding author upon reasonable request.

Authors' contributors: CJO and CIA conceptualized the study. CJO, IIO, IIN and UUA designed the questionnaire. CJO, $U A U$, and IIO acquired and performed data collection and analysis. CJO drafted the first copy of the manuscript. CIA conducted a critical review of the manuscript. All authors read and approved the final manuscript.

\section{References}

1. Ballard O, Morrow AL. Human milk composition: nutrients and bioactive factors. Pediatr Clin North Am. 2013;60(1):49-74. Doi: 10.1016/j.pcl.2012.10.002.

2. Cai X, Wardlaw T, Brown DW. Global trends in exclusive breastfeeding. Int Breastfeed J. 2012;7(1):12. Doi: 10. 1186/1746-4358-7-12.

3. Karim F, Billah SM, Chowdhury MAK, Zaka N, Manu A, Arifeen SE, et al. Initiation of breastfeeding within one hour of birth and its determinants among normal vaginal deliveries at primary and secondary health facilities in Bangladesh: A case-observation study. PLoS One. 2018; 13(8):e0202508. Doi: 10.1371/journal.pone.0202508.

4. John JR, Mistry SK, Kebede G, Manohar N, Arora A. Determinants of early initiation of breastfeeding in Ethiopia: a population-based study using the 2016 demographic and health survey data. BMC Pregnancy Childbirth. 2019;19(1):69. Doi: 10.1186/s12884-0192211-0.

5. Takahashi K, Ganchimeg T, Ota E, Vogel JP, Souza JP, Laopaiboon $\mathrm{M}$, et al. Prevalence of early initiation of breastfeeding and determinants of delayed initiation of breastfeeding: secondary analysis of the WHO Global Survey. Sci Rep. 2017;7:44868. Doi: 10.1038/srep44868.

6. Friedrich M. Early initiation of breastfeeding. JAMA. 2018;320(11):1097. Doi:10.1001/jama.2018.13372.

7. Ahmed AE, Salih OA. Determinants of the early initiation of breastfeeding in the Kingdom of Saudi Arabia. Int 
Breastfeed J. 2019;14:13. Doi:10.1186/s13006-019-0207-z.

8. Sim TF, Hattingh HL, Sherriff J, Tee LB. The use, perceived effectiveness and safety of herbal galactagogues during breastfeeding: a qualitative study. Int J Environ Res Public Health. 2015;12(9):11050-71. Doi: 10.3390/ ijerph120911050.

9. Kent JC, Gardner H, Geddes DT. Breastmilk production in the first 4 weeks after birth of term infants. Nutrients. 2016;8(12):756. Doi: 10.3390/nu8120756

10. Kavle JA, LaCroix E, Dau H, Engmann C. Addressing barriers to exclusive breast-feeding in low- and middle-income countries: a systematic review and programmatic implications. Public Health Nutr. 2017;20(17):3120-34. Doi: $10.1017 /$ S1368980017002531.

11. Khanal V, Scott JA, Lee AH, Karkee R, Binns CW. The supplemental use of infant formula in the context of universal breastfeeding practices in Western Nepal. BMC Pediatr. 2016;16:68. Doi: 10.1186/s12887-016-0602-1.

12. Monteban, M. Maternal knowledge and use of galactagogues in andean communities of Cusco, Peru. Ethnobiology Letters. 2017;8(1):81-9. Doi: 10.14237/ebl.8.1. 2017.935

13. Ozalkaya E, Aslandogdu Z, Ozkoral A, Topcuoglu S, Karatekin G. Effect of a galactagogue herbal tea on breast milk production and prolactin secretion by mothers of preterm babies. Niger J ClinPract. 2018;21(1):38-42. Doi: 10.4103/1119-3077.224788.

14. Mortel M, Mehta SD. Systematic review of the efficacy of herbal galactogogues. J Hum Lact. 2013;29(2):154-62. Doi:10.1177/0890334413477243.

15. Wanjohi M, Griffiths P, Wekesah F, Muriuki P, Muhia N, Musoke RN, et al. Sociocultural factors influencing breastfeeding practices in two slums in Nairobi, Kenya. Int Breastfeed J. 2017;12:5. Doi: 10.1186/s13006-0160092-7.

16. Gbadamosi IT, Okolosi O. Botanical galactogogues: nu- tritional values and therapeutic potentials. J Appl Biosci. 2013;61:4460-9. Doi: 10.4314/jab.v61i0.85594.

17. Nwagu EN, Dibia SIC, Odo AN. Socio-cultural norms and roles in the use and abuse of alcohol among members of a rural community in Southeast Nigeria. Health Educ Res. 2017;32(5):423-36. Doi: 10.1093/her/cyx058.

18. Ikegwu TM, Okafor GI, Ochiogu IS. Effect of preservation methods of oil palm sap (Elaeis guineensis) on the reproductive indices of male wistar rats. J Med Food. 2014;17(12):1368-74. Doi: 10.1089/jmf.2013.0087.

19. Santiago-Urbina JA, Ruíz-Terán F. Microbiology and biochemistry of traditional palm wine produced around the world. Int Food Res J. 2014;21(4):1261-9.

20. Bazzano AN, Hofer R, Thibeau S, Gillispie V, Jacobs M, Theall KP. A review of herbal and pharmaceutical galactagogues for breast-feeding. Ochsner J. 2016;16(4): 511-24. PMID: 27999511.

21. Penagos Tabares F, Bedoya Jaramillo JV, Ruiz-Cortés ZT. Pharmacological overview of galactogogues. Vet Med Int. 2014;2014:602894. Doi: 10.1155/2014/602894.

22. Grzeskowiak LE, Wlodek ME, Geddes DT. What evidence do we have for pharmaceutical galactagogues in the treatment of lactation insufficiency?-a narrative review. Nutrients. 2019;11(5):974. Doi: 10.3390/nu11050974.

23. Dandotiya H, Singh G, Kashaw SK. The galactagogues used by Indian tribal communities to overcome poor lactation. Int J Biotechnol Bioengen Res. 2013;4(3):243-8.

24. Othman N, Lamin AC, Othman CN. Exploring behavior on the herbal galactagogue usage among malay lactating mothers in Malaysia. Proced-Soc Behav Sci. 2014;153:199-208. Doi: 10.1016/j.sbspro.2014. 10.054.

25. Ojo OC. Agboola SA. Antibacterial effects of palm wine (Elaeis guineensis) on Salmonella typhi isolated from different sources. Int J Product Res. 2019;2(4):1-2. Doi: 10.9734/ijpr/2019/v2i430080. 